\title{
LEUCOENCEFALOPATIA MEGALENCEFÁLICA COM SUBSTÂNCIA BRANCA EVANESCENTE E CISTOS SUBCORTICAIS
}

\author{
Hélio Araújo Oliveiraㄹ, Marbene Guedes Machado², Alan Chester Feitosa de Jesus³, \\ Emanoella Faro de Oliveira ${ }^{4}$, Arthur Maynart Pereira Oliveira ${ }^{4}$
}

\begin{abstract}
RESUMO - Apresentamostrêscasos de leucoencefalopatia megalencefálica com substancia branca evanescente e cistossubcorticais, diagnosticados através da ressonância nuclear magnética.Oscasosestudados apresentam quadro clinico e radiológico de acordo com os critérios diagnósticos estabelecidosna descrição inicial desta enfermidade. São discutidos os aspectos clínicos e neuroradiológicos.
\end{abstract}

PALAVRAS-CHAVE: leucoencefalopatia, megalencefalia, substância branca evanescente, síndrome de van der Knaap.

\begin{abstract}
Megalencephalic leukoencephalopathy with vanishing white matter and cystic formation
ABSTRACT - We present three cases of megalencephalicleukoencephalopathy with vanishing white matter and cysticformation in both temporal lobes, diagnosed through magnetic resonance imaging. All the cases presented dinical and radiological aspectsaccording to the diagnostic criteria that were established in the initial description of the syndrome. Clinical and radiological aspects are discussed.
\end{abstract}

KEY WORDS: leukoencephalopathy, megalencephaly, vanishing white matter, van der Knaap syndrome.

Em 1995, van der Knaap et al. ${ }^{1}$ descreveram pela primeira vez uma síndrome caracterizada pela presença de leucoencefalopatia e megalencefalia de início na infância com imagens características através da ressonância nuclear magnética (RNM). Doisanos apósosprimeiros relatose já com estudos mais aprofundados da nova enfermidade, foram propostos pelos autores os critérios para diagnóstico: 1-Desenvolvimento psicomotor inicial normal ou moderadamente afetado; 2 - Aparecimento na infância de episódios de deterioração neurológica ou curso crônico progressivo; esta deterioração pode ser precedida por quadro infeccioso ou por traumatismo cranioencefálico moderado; 3- Presença de quadro neurológico caracterizado por sinaispiramidais, ataxia cerebelar, atrofia óptica, epilepsia e preservação das funções mentais; 4 - Envolvimento simétrico da substância branca dos hemisférios cerebraisosquaisapresentamà RNM sinal semelhante ao líquido céfalorraquidiano (LCR), bem como atrofia cerebelar com envolvimento primário do vermis ${ }^{2}$. A idadenão foi usada como critério diagnóstico porque estudosrealizadoscom relação à variação fenotípica da doença demonstraram não haver relação entre a idade de inicio do aparecimento dos sintomase a evolução³.

Depois dos trabalhos iniciais, vários autores têm relatado a ocorrência desta nova enfermidade na literatura pertinente ${ }^{4-12}$. Por se tratar de enfermidade que apresenta diferentes alterações reveladas pela RNM, é que trabalhos recentes têm procurado abolir a denominação de síndrome de van der Knaap, para referir uma nomenclatura baseada nos achados neurorradiológicos: leucoencefalopatia megalencefálica com cistossubcorticaisou leucoencefalopatia megalencefálica com substância branca evanescente (alternativamente chamada de ataxia da infância com hipomielinização central $)^{13}$. Apresentamostrêscasos de leucoencefalopatia megalencefálica com substância branca evanescente e cistos subcorticais, os quais se enquadram nos critérios diagnósticos estabelecidos para esta enfermidade.

\section{CASOS}

Caso 1 - Moça de 14 anos, natural e procedente de Aracaju. Foi atendida no ambulatório de Neurologia

Serviço de Neurologia do Hospital Universitário da Universidade Federal de Sergipe, Aracaju SE, Brasil (UFS): ${ }^{1}$ Professor do Departamento de Medicina; ${ }^{2}$ Neuropediatra do Serviço de Neurologia; ${ }^{3}$ Medico Residente; ${ }^{4}$ Acadêmicos do Curso de Medicina da UFS.

Recebido 26 Janeiro 2004, recebido na forma final 21 Junho 2004. Aceito 2 Agosto 2004.

Dr. Hélio Araújo Oliveira - Rua Reginaldo Passos Pina 261 - 49040-720 Aracaju SE - E-mail: helio@infonet.com.br 
apresentando dificuldade para deambular que teve inicio no período pré-escolar com progressão do quadro. Na história evolutiva constatou-se ter nascido de parto normal a termo sem indícios de anóxia pré, peri ou pós-natal; foi relatado discreto atraso de desenvolvimento neuropsicomotor, tendo adquirido marcha independente aosdois anos de idade. Desde o nascimento, apresentava aumento do perímetro cefálico, tendo sido investigada com ultrassonografia que mostrou sistema ventricular morfologicamente normal. Aosquatro anos de idade, após traumatismo craniano leve, apresentou episódio de perda dossentidosseguido de crise convulsiva tônico-clônica generalizada. A partir deste episodio, passou a apresentar dificuldade para deambular de caráter progressivo com comprometimento da qualidade de vida e da cognição. A história familiar não revelou consangüinidade entre os pais ou a presença de outras doençasneurológicas. O exame físico foi normal; perímetro craniano de $58 \mathrm{~cm}(+2,56$ DP acima do percentil $98 \%$ ). Exame neurológico: respondia assolicitações verbais, mantinha diálogo coerente e a voz tinha um timbre escandido; marcha pareto-espástica com diminuição da força muscular mais acentuada nos membrosinferiores; hiperreflexia profunda generalizada com sinal de Babinski bilateralmente; hipertonia moderada bilateral; tremor cinético nas mãos e incoordenação motora. Nervos cranianos normais. Os exames laboratoriais de rotina foram normais. O EEG não mostrou alterações especificas. A tomografia computadorizada (TC) mostrou presença de hipodensidade da substância branca cerebral mais evidente no lobo temporal, bilateralmente. A RNM revelou: macrocefalia com alteração difusa da intensidade de sinal da substância branca noslobosfrontal, temporal e parietal, bilateralmente, com hipossinal nas seqüências pesadas em T1 e hiperssinal nas seqüências pesadas em T2 e FLAIR (aspecto desmielinizante da substância branca com distribuição bilateral e simétrica); áreas de hipossinal nasseqüências pesadas em T1 e FLAIR e de hipersinal em T2, com aspecto cavitário ou cístico, com conteúdo do sinal idêntico ao LCR, localizadasna substância branca do pólo anterior do lobo temporal bilateralmente (Fig 1).
Caso 2 - Mulher de 20 anos, natural e procedente de Aracaju. Foi atendida no Ambulatório de Neurologia com queixa de dificuldade para deambular que teve inicio na infância. Na história evolutiva constatamoster nascido de parto cesáreo, com sofrimento fetal moderado. Iniciou deambulação e linguagem aos dois anos de idade e nesta época já era notado macrocrania moderada. Aostrês anos de idade apresentou o primeiro episódio de crise convulsiva tônico-clônica generalizada com predomínio no dimídio direito; a partir de então, iniciou tratamento com drogas antiepilépticas com resposta insatisfatória. Nesta época começou a apresentar dificuldade para deambular, que no início era de intensidade moderada, evoluindo cada vez mais para maior envolvimento da deambulação. Iniciou escolaridade com quatro anos de idade sendo percebida dificuldade crescente da cognição; aos sete anos de idade não tinha condições para freqüentar a escola, não só pela dificuldade cognitiva como pelo comprometimento da deambulação e da coordenação dos movimentos voluntários. A história familiar não revelou consangüinidade, nem a existência de outras doenças neurológicas. O exame físico foi normal; perímetro craniano de $61 \mathrm{~cm}$ (+3,61 DP acima do percentil 98\%). Exame neurológico: a paciente apresentava-se em cadeira de rodas; estava alerta e orientada, mantinha um diálogo coerente, grande dificuldade de expressão às custas de voz escandida e incoordenada; tetraparesia espástica com predominância nos membros inferiores; hiperreflexia profunda generalizada, sinal de Babinski bilateral; incoordenação motora acentuada. Nervoscranianos normais, exceto pela presença de palidez moderada da papila, bilateralmente, com diminuição da acuidade visual. Os exames laboratoriais de rotina foram normais. A RNM do crânio revelou: macrocefalia, alteração difusa da intensidade do sinal da substância branca nos lobos frontal, temporal e parietal bilateralmente, com hiposinal nasseqüências pesadas em Tl e hipersinal nas seqüências pesadas em T2 e FLAIR (aspecto desmielinizante difuso da substância branca com distribuição bila-

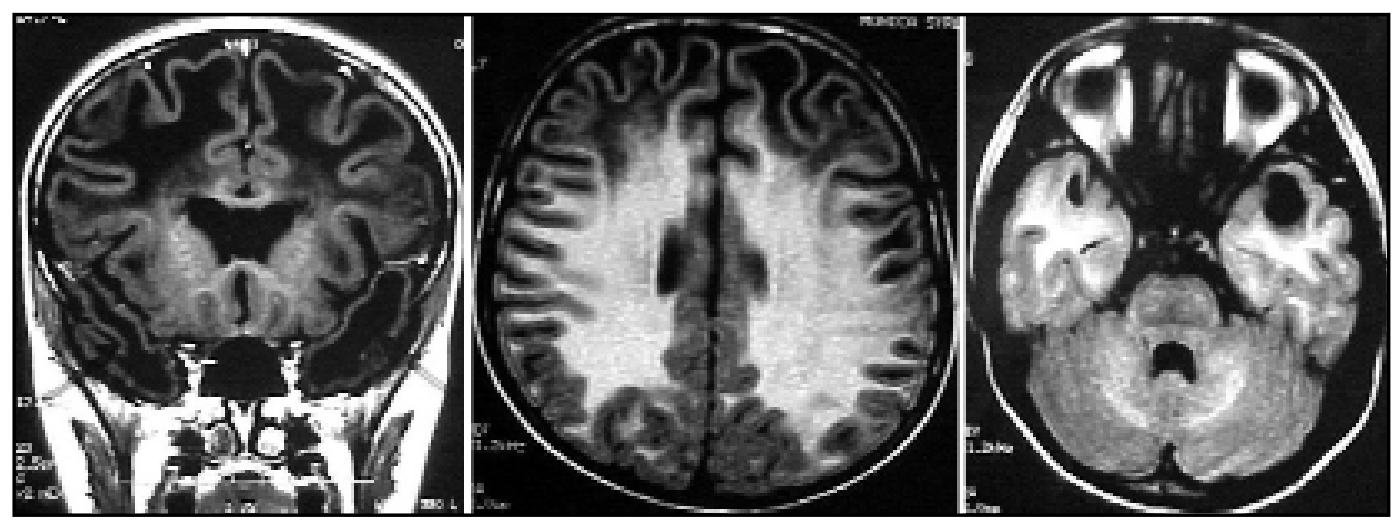

Fig 1. Caso 1. RNM demonstrando alteração difusa da intensidade do sinal da substância branca, com aspecto desmielinizante, simétrico com formações lacunares no polo do lobo temporal bilateralmente, mais evidente à esquerda, observando-se hipossinal na seqüência pesada em T1 e hipersinal na seqüência pesada em T2. 

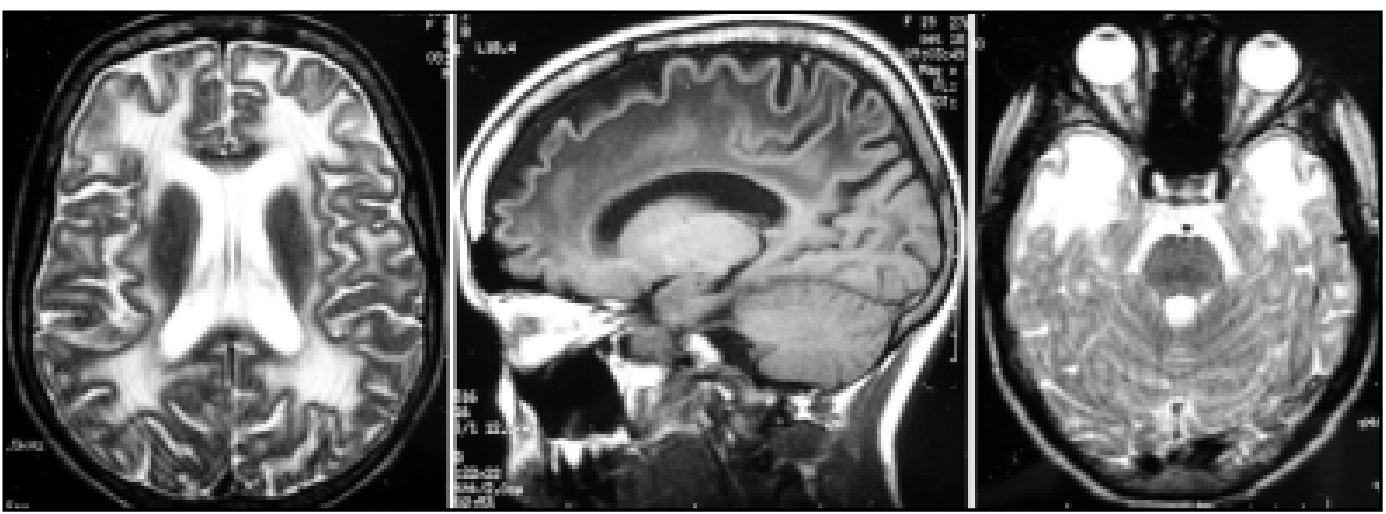

Fig 2. Caso 2. RNM demonstrando alteração difusa da intensidade do sinal da substancia branca com aspecto desmielinizante e distribuição bilateral e simétrica; área de hipossinal na seqüência pesada em T1 e hipersinal na seqüência pesada em T2 com aspecto cavitário no pólo anterior do lobo temporal bilateralmente.
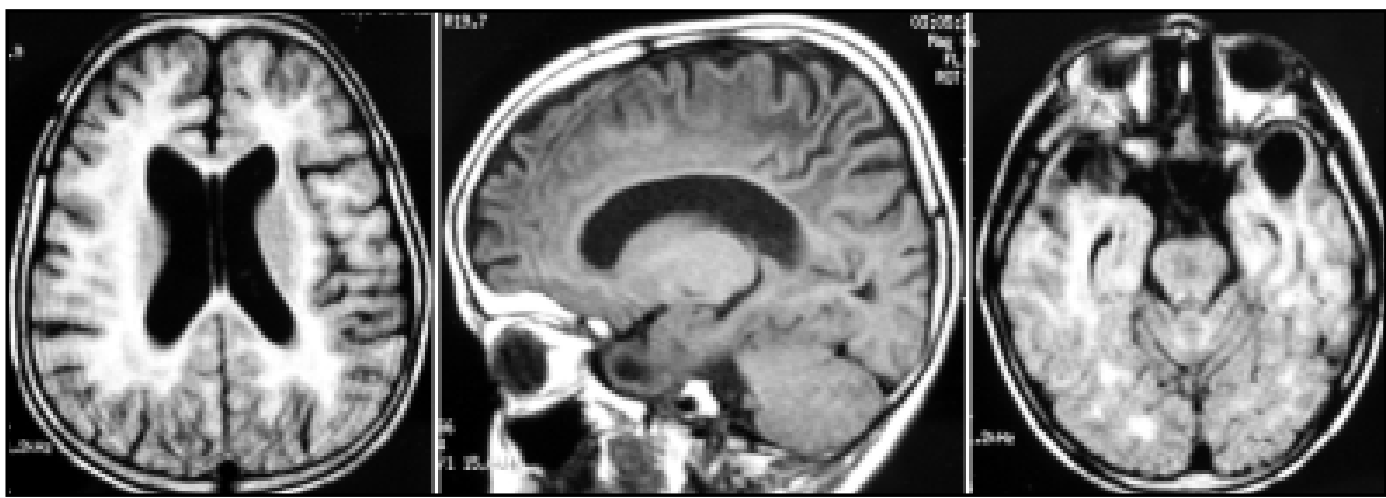

Fig 3. Caso 3. RNM demonstrando alteração difusa da intensidade do sinal da substância branca com hipossinal na seqüência pesada em T1 e hipersinal na seqüência pesada em T2, com aspecto de desmielinização. Cavidades císticas no pólo anterior do lobo temporal bilateralmente.

teral e simétrica); áreas de hipossinal nas seqüências pesadas T1 e FLAIR e hipersinal em T2, com aspecto cavitário ou cístico e conteúdo do sinal idêntico ao LCR, localizado na substância branca do pólo anterior do lobo temporal bilateralmente. (Fig 2).

Caso 3 - Menino de 13 anos, natural e procedente de Aracaju. Foi atendido no Ambulatório de Neurologia com queixa de crises convulsivas parciais complexase dificuldade para deambular. A historia evolutiva mostrou parto normal a termo com sofrimento fetal moderado; iniciou lalação com um ano de idade e a deambulação com 18 meses. Desde os quatro meses de idade, foi percebida macrocefalia, tendo sido investigada através de ultrassonografia, que demonstrou não haver alteração morfológica do sistema ventricular, e de TC que mostrou presença de alterações da substância branca compatíveis com leucodistrofia. Aos dois anos de idade apresentou episodio de crise convulsiva generalizada apóstraumatismo de crânio leve. Após este, o quadro convulsivo tornouse freqüente com o surgimento de crises parciais complexasintercaladas por abalos mioclônicos, controladas com o uso de drogas antiepilépticas. A partir de então, passou a apresentar dificuldade para deambular cuja intensidade foi progressiva e atualmente só deambula com ajuda. Não foi constatada consangüinidade entre os pais bem como doenças neurológicas na família. 0 exame físico foi normal. Perímetro craniano de $64 \mathrm{~cm}$ (+7,03 DP acima do percentil 98\%). Exame neurológico: alerta e orientado, linguagem comprometida principalmente na expressão com voz escandida e atáxica; tetraparesia espástica, hiperreflexia profunda generalizada, sinal de Babinski bilateralmente, força muscular preservada; marcha atáxica necessitando de ajuda, incoordenação motora acentuada. Nervos cranianos normais. Os exames laboratoriais de rotina não mostraram alterações. EEG: paroxismos de complexos poliponta-onda difusose bissincrônicos. Iniciou tratamento com clonazepan (1mg/dia) ocorrendo redução da freqüência das crises. A RNM de crânio revelou: macrocefalia; alteração difusa da intensidade do sinal da substância branca nos lobos frontal, temporal e parietal bilateralmente, com hiopossinal nas seqüências pesadas em $\mathrm{T} 1$ e hipersinal nas seqüências pesadas em T2 e FLAIR (aspecto desmie- 
linizante difuso da substância branca com distribuição bileteral e simétrica); áreas de hipossinal nas seqüências pesadas em T1 e FLAIR e hipersinal em T2, com aspecto cavitário ou cístico , e conteúdo do sinal idêntico ao LCR, localizado na substância branca do pólo anterior do lobo temporal bilateralmente. (Fig 3).

\section{DISCUSSÃO}

A leucoencefalopatia megalencefálica com substância branca evanescente e cistossubcorticais de descrição relativamente recente ${ }^{1}$ tem como característica principal a presença de megalencefalia de inicio precoce, associada a leucodistrofia difusa e simétrica e cavitações localizadas no lobo temporal, bilateralmente. É especialmente definida pela RNM e pela RNM com espectroscopia, existindo grande discrepância entre a intensidade dos achados neuroradiológicos e a intensidade do quadro dínico, sendo os primeiros acentuados e extensos no sistema nervoso central (SNC), enquanto o segundo pode ser de intensidade variável.

Os casos relatadosdemonstram as mesmascaracterísticas da discrição original, isto é, todos apresentam leucodistrofia difusa e simétrica bem como cavidades císticas na região anterior do lobo temporal bilateralmente, sem envolvimento do tálamo e dos núcleos da base, na presença de quadro clínico bastante variável tanto no início do aparecimento dos sinaise sintomas quanto na evolução da doença. Nos casos 1 e 3, a macrocrania foi evidenciada desde o nascimento; no caso 2, a macrocrania só foi percebida aos dois anos de idade. $\mathrm{O}$ inicio da sintomatologia teve como fator desencadeante a ocorrência de trauma de crânio (casos 1 e 3) e de crise convulsiva (caso 2). A evolução da sintomatologia foi bastante difente; no caso 1 , a evolução tem sido mais lenta, a paciente ainda deambula apesar da existência de sinais e sintomas de envolvimento do sistema piramidal e do cerebelo; já os casos 2 e 3 apresentam sintomatologia mais comprometedora que ostorna dependentes. É importante ressaltar que a idade não tem influência na evolução da enfermidade ${ }^{3}$.Todos os três pacientes apresentam epilepsia, cuja ocorrência na literatura é variável, não constituindo achado fundamental.

A leucodistrofia megalencefálica com substância branca evanescente é doença autossômica recessiva, geneticamente já definida com a demonstração do gene no cromossoma 3q2714. Estudosmais avançados demonstram que diferentes mutações nos genes das diversas subunidades do fator EIF2B, também podem causar estas alterações, tendo sido primeiramente referido as mutações do gene da subunidade 5 (EIF2B5), podendo ocorrer também em outras subunidades (EIF2B1 a EIF2B4) ${ }^{15,16}$. A leucoencefalopatia megalencefálica com cistos subcorticais é também considerada doença autossômica recessiva, mutação no gene $\mathrm{MLCl}$ tendo sido descrita como responsável por esta forma clínica ${ }^{17}$.

O defeito básico da doença é desconhecido. $O$ caráter autossômico recessivo poderia indicar um erro inato do metabolismo; entretanto, pesquisas realizadasaté agora não demonstraram nenhuma alteração bioquímica, exceto a ocorrência de aumento de glicina no LCR de pacientes portadores de leucoencefalopatia megalencefálica com substância branca evanescente ${ }^{18}$ enquanto nos portadoresde leucoencefalopatia megalencefálica com cistos subcorticais estes achados não foram comprovados $^{13,19}$. A possibilidade da existência de um defeito genético ao nível da barreira hematoencefálica poderia sugerir a causa do aumento do volume de água no espaço extradural, não existindo comprovação definitiva ${ }^{1}$. O estudo anátomo-patológico, realizado em um doscasos da descrição inicial, mostrou córtex cerebral normal e a anormalidade da substância branca iniciando-se logo abaixo; em algumas áreas as fibras em $U$ estavam parcialmente preservadas contendo mielina. A substância branca entre o epêndima e as fibras em U estava destruída com presença de vacúolos túrgidos cobertos por bainhas multilaminares ${ }^{2}$.

O diagnóstico é definido pela RNM que mostra leucodistrofia difusa e simétrica comáreas anormais de aumento de intensidade na substância branca e no LCR, acompanhadas de lesões císticas na região anterior do lobo temporal cuja intensidade e sinal do seu conteúdo é semelhante ao sinal de intensidade do LCR $^{1}$. Estudos feitos através da RNM com espectroscopia têm demonstrado o desaparecimento quase que completo de todos os sinais normais da substância branca e a presença de glicose e lactato compatível coma existência de maior quantidade de LCR e diminuição do tecido cerebral2,18-20.

Considerando a presença da leucodistrofia um marco importante para o diagnóstico desta enfermidade, é necessário considerar no diagnóstico diferencial outrasenfermidadesque também cursam com alterações da substância branca tais como: leucodistrofia metacromática (autossômica recessiva por deficiência da enzima arilsulfatase); adrenoleucodistrofia (autossômica recessiva ligada ao 
cromossoma X por deficiência de ácidosgraxosde cadeia longa); doença de Canavan (envolvimento do tálamo e dos núcleos da base); doença de Alexander (envolvimento periventricular com cavitações na região periventricular frontal); acidúria L2-hidroxiglutárica (envolvimento dos núcleos da base e do vermis cerebelar e do núcleo denteado) ${ }^{1}$. As duasúltimasentidadestambém cursam com megalencefalia. Programas especiais com modelos para reconhecimento das alterações das imagens da RNM, correspondentes às anormalidades da substância branca, têm ajudado na determinação do diagnóstico, proporcionando maior especificidade na interpretação das imagens ${ }^{21}$.

Na presença de megalencefalia sem alterações neurológicas definidas, com evidência de lesão da substância branca (leucodistrofia), associado a presença de cistosno lobo temporal comprovadospela RNM, mesmo sem a realização de RNM com espectroscopia ${ }^{4-6,8,10,11}$ deve ser considerado o diagnóstico de leucoencefalopatia megalencefálica com substância branca evanescente e cistossubcorticais descrita por van der Knaap.

\section{REFERÊNCIAS}

1. van der Knaap MS, Barth P G, Stronik H, et al. Leukoencephalopathy with swelling and a discrepantly mild clinical course in eight children. Ann Neurol 1995;37:324-334.

2. van der Knaap M S, Marth P G, Gabreels F G, et al. A new leukoencephalopathy with vanishing white matter. Neurology 1997;48:845-855.

3. van der Knaap M S, Kamphorst W, Barth P G, E et al. Phenotypic variation in leukoencephalopathy with vanishing white matter. Neurology 1998;51:540-547.

4. Olivier M, Lenard HG, Aksu F, Gartner J. Anew leukoencephlapathy with bilateral anterior temporal lobe cysts. Neuropediatrics 1998;29:225-228.

5. Yakinei C, Soyles H, Kutler N O, Seuer R N. Leukoencephalopathy with a mild clinical course: case report. Computeerized, imaging and graphics 1999;23:169-172.

6. Sugiuro C, Miyata H, Oka A, et al. A Japonese girl with leukoencephalopathy with vanishin white matter. Brain Dev 2001;23:58-61.

7. Ben-Zeev B, Gross V, Kushuir T, et al. Vacuolating megalencephalic leukoencephalopathy in 12 Isra patients. J Child Neurol 2001;16:93-99.

8. Santos-Moreno M T, Campos-Castello J. Non specific leukoencephalopathy: a new case of vacuolizing leukoencephalopathy with megalencephaly. Rev Neurol 2002;34:19-27.

9. Gelar F, Calli C, Apoydin M, Erdem G. van der Knaap's leucoencephalopathy: report of five new cases with emphasis an diffusionweighted MRI findings. Neuroradiology 2002;44:625-630.

10. Rosemberg S, Leite CC, Arita FN, Kliemann SF, Lacerda MT. Leukoencephalopathy with vanishing white matter: report of four cases from three unrelated Brazilian families. Brain Dev 2002;24:250-256.

11. Cavalcante C E, Nogueira A. Sindrome de van der Knaap: megalencefalia com leucodistrofia: a respeito de dois casos na mesma família. Arq Neuropsiquiatr 2000;58:157-161.

12. Battini R, Bianchi M C, Toretti M, Guzzetta A, Ciani G. Leukoencephalopathy with bilateral anterior temporal lobe cysts: a further case of this new entity. J Child Neurol 2002;17:773-776.

13. van der Knaap M S. Forget abaut "van der Knaap syndrome", forget abaut glycine. Am J Neuroradiol 2003;24:1030.

14. Leegwater PA, Konst AA, Kuyt B, et al. The gene for leukoencephalopathy with vanishing white matter is located on chromosome 3q27. Am J Hum Genet 1999;65:728-734.

15. van der Knaap MS, Leegwter P A, Konst A A, et al. Mutations in each of the five subunits of translation initiation factor eIF2B can cause leukoencephalopathy with vanishing white matter. Ann Neurol 2002;51:264-267.

16. Leegwater P A,Pronk J C, van der Knaap M S. Leukoencephalopathy with vanishing white matter: from magnetic resonance imaging pattern to five genes. J Child Neurol 2003;18:639-645.

17. Sinhal BS, Gorospe J R, Naidu S. Megalencephalic leukoencephalopathy with subcotical cysts . J Child Neurol 2003;18:645-652.

18. van der Knaap MS, Wevers R A, Kure S, et al. Incresed cerebrospinhal fluid glycine: a biochemical marker for a leukoencephalopathy with vanishing white matter. J Child Neurol 1999;14:728-731.

19. Sener R N. Demonstration of glycine peaks at $3,50 \mathrm{ppm}$ in a patient with van der Knaap syndrome. Am J Neuroradiol 2001;22:1587-1589.

20. De Stefano N, Balestri P, Datti M T, et al. Severe metabolic abnormalities in the white matter or patients with vacuolating megalencephalic leukoencephalopathy with subcortical cysts: a proton MR spectroscopic imaging study. J Neurol 2001;248:403-409.

21. van der Knaap MS, Volk J, de Neeling N, Nante JJP. Patern recognition in magnetic resonance imaging of white matter disorders in children an young adults. Neuroradiology 1991;33:478-493. 